\title{
Correction to: Cognitive Impairment in SLE: Mechanisms and Therapeutic Approaches
}

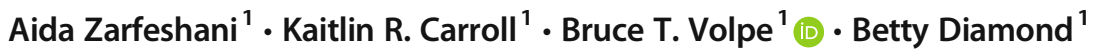 \\ Published online: 11 May 2021 \\ (C) Springer Science+Business Media, LLC, part of Springer Nature 2021
}

\section{Correction to: Current Rheumatology Reports. https://doi.org/10.1007/s11926-021-00992-1}

The original version of this article unfortunately contained mistakes. The details are given below.

Currently published:

166.• Harrison MJ, Ravdin LD, Lockshin MD. Relationship between serum NR2a antibodies and cognitive dysfunction in systemic lupus erythematosus. Arthritis and rheumatism. 2006;54(8): 2515-22. https://doi.org/10.1002/art.22030 http:/www.ncbi.nlm.nih.gov/pubmed/16868972. This study found anti-dsDNA/NMDAR antibodies in brains of SLE patients colocalized with NR2A, and cause neuronal death and cognitive dysfunction in mice.

167. Kowal C, DeGiorgio LA, Lee JY, Edgar MA, Huerta PT, Volpe BT, et al. Human lupus autoantibodies against NMDA receptors mediate cognitive impairment. Proceedings of the National Academy of Sciences. 2006;103(52):19854-9. This study found serum anti-NR2 antibodies associated with depressive mood in SLE patients.

168. Lapteva L, Nowak M, Yarboro CH, Takada K, Roebuck-Spencer T, Weickert T, et al. Anti-N-methyl-Daspartate receptor antibodies, cognitive dysfunction, and depression in systemic lupus erythematosus. Arthritis and rheumatism. 2006;54(8):2505-14. https://doi.org/10.1002/art. 22031 http://www.ncbi.nlm.nih.gov/pubmed/16868971.

This study found an association of anti-NMDAR and

The online version of the original article can be found at https://doi.org/ 10.1007/s11926-021-00992-1

Betty Diamond

bdiamond@northwell.edu

1 Institute of Molecular Medicine, Feinstein Institutes for Medical Research, 350 Community Drive, Manhasset, NY 11030, USA
anti-P antibodies with cognitive dysfunction in SLE patients with active disease.

169. Massardo L, Bravo-Zehnder M, Calderon J, Flores P, Padilla O, Aguirre JM, et al. Anti-N-methyl-D-aspartate receptor and antiribosomal-P autoantibodies contribute to cognitive dysfunction in systemic lupus erythematosus. Lupus. $2015 ; 24$ (6):5 58-68. https://doi.org/10.1177/ 0961203314555538 https:/www.ncbi.nlm.nih.gov/pubmed/ 25318968.

Remove the enhancement from Reference 166.

To reference 167 add the enhancement as shown:

167. Kowal C, DeGiorgio LA, Lee JY, Edgar MA, Huerta PT, Volpe BT, et al. Human lupus autoantibodies against NMDA receptors mediate cognitive impairment. Proceedings of the National Academy of Sciences. 2006;103(52):19854-9.. This study found anti-dsDNA/ NMDAR antibodies in brains of SLE patients colocalized with NR2A, and cause neuronal death and cognitive dysfunction in mice.

To reference 168 add the enhancement as shown:

168. Lapteva L, Nowak M, Yarboro CH, Takada K, Roebuck-Spencer T, Weickert T, et al. Anti-N-methyl-Daspartate receptor antibodies, cognitive dysfunction, and depression in systemic lupus erythematosus. Arthritis and rheumatism. 2006;54(8):2505-14. https://doi.org/10.1002/art. 22031 http://www.ncbi.nlm.nih.gov/pubmed/16868971.

This study found serum anti-NR2 antibodies associated with depressive mood in SLE patients.

To reference 169 add the enhancement as shown: 169. Massardo L, Bravo-Zehnder M, Calderon J, Flores P, Padilla O, Aguirre JM, et al. Anti-N-methyl-D-aspartate receptor and antiribosomal-P autoantibodies contribute to cognitive dysfunction in systemic lupus erythematosus. Lupus. $2015 ; 24(6): 558-68$. https://doi.org/10.1177/ 
$0961203314555538 \mathrm{https} / / /$ www.ncbi.nlm.nih.gov/pubmed/ 25318968. This study found an association of antiNMDAR and anti-P antibodies with cognitive dysfunction in SLE patients with active disease.

\section{Currently published:}

173.• Chang EH, Volpe BT,Mackay M, Aranow C, Watson $\mathrm{P}$, Kowal C, et al. Selective impairment of spatial cognition caused by autoantibodies to the N-methyl-D-aspartate receptor. EBioMedicine. 2015;2(7):755-64. This study demonstrated that DNRAbs can also induce neuronal loss in the amygdala and emotional behavioral abnormalities when epinephrine is used to induce $\mathrm{BBB}$ permeability.

174. Huerta PT, Kowal C, DeGiorgio LA, Volpe BT, Diamond B. Immunity and behavior: antibodies alter emotion. Proceedings of the National Academy of Sciences of the United States of America. 2006;103(3):678-83. Epub 2006/01/13. https://doi.org/10.1073/pnas.0510055103. PubMed PMID: 16407105; PMCID: 1334673. http://www. ncbi.nlm.nih.gov/pubmed/16407105.

Remove the enhancement from reference 173.

Add the enhancement to reference 174 as shown:

174. Huerta PT, Kowal C, DeGiorgio LA, Volpe BT, Diamond B. Immunity and behavior: antibodies alter emotion. Proceedings of the National Academy of Sciences of the United States of America. 2006;103(3):678-83. Epub 2006/01/13. https://doi.org/10.1073/pnas.0510055103. PubMed PMID: 16407105; PMCID: 1334673. http://www. ncbi.nlm.nih.gov/pubmed/16407105. This study demonstrated that DNRAbs can also induce neuronal loss in the amygdala and emotional behavioral abnormalities when epinephrine is used to induce BBB permeability.

Currently published:

186.• Kowal C, DeGiorgio LA, Nakaoka T, Hetherington H, Huerta PT, Diamond B, Volpe BT. Cognition and immunity; antibody impairs memory. Immunity. 2004;21(2):179-188. Epub 2004/08/17. https://doi.org/10.1016/j.immuni.2004.07. 011. http://www.ncbi.nlm.nih.gov/pubmed/15308099. This study found that transient exposure to DNRAbs induces long term neuronal dysfunction mediated by activated microglia and C1q, which can be prevented with ACE inhibition in mice.

187. Nestor J, Arinuma Y, Huerta TS, Kowal C, Nasiri E, Kello N, Fujieda Y, Bialas A, Hammond T, Sriram U, Stevens B, Huerta PT, Volpe BT, Diamond B. Lupus antibodies induce behavioral changes mediated by microglia and blocked by ACE inhibitors. The Journal of experimental medicine. 2018;215(10):2554-66. Epub 2018/09/07. https://doi. org/10.1084/jem.20180776. PubMed PMID: 30185634;
PMCID: PMC6170183. https://www.ncbi.nlm.nih.gov/ pubmed/30185634.

Remove enhancement from reference 186.

Add the enhancement to 187 as shown:

187. Nestor J, Arinuma Y, Huerta TS, Kowal C, Nasiri E, Kello N, Fujieda Y, Bialas A, Hammond T, Sriram U, Stevens B, Huerta PT, Volpe BT, Diamond B. Lupus antibodies induce behavioral changes mediated by microglia and blocked by ACE inhibitors. The Journal of experimental medicine. 2018;215(10):2554-66. Epub 2018/09/07. https://doi. org/10.1084/jem.20180776. PubMed PMID: 30185634; PMCID: PMC6170183. https://www.ncbi.nlm.nih.gov/ pubmed/30185634. This study found that transient exposure to DNRAbs induces long term neuronal dysfunction mediated by activated microglia and C1q, which can be prevented with ACE inhibition in mice.

Currently published:

199. Vinet E, Bernatsky S, Pineau CA, Clarke AE, Nashi EP, Scott $\mathrm{S}$, et al. Increased male-to-female ratio among children born women with systemic lupus erythematosus: comment on the article by Lockshin et al. Arthritis and rheumatism. 2013;65(4):1129. https://doi.org/10.1002/art.37852 https:// www.ncbi.nlm.nih.gov/pubmed/23335044. This group reviews the incidence and potential risk factors for stillbirth and neurodevelopmental disorders in children born to women with SLE, including in utero exposure to maternal autoantibodies and cytokine levels.

200. Vinet E, GenestG, Scott S, Pineau CA, Clarke AE, PlattRW, et al. Brief report: causes of stillbirths in women with systemic lupus erythematosus. Arthritis Rheumatol. 2016;68(10):2487-91. https://doi.org/10.1002/art.39742 https:/www.ncbi.nlm.nih.gov/pubmed/27159385.

Remove the enhancement from reference 199.

Add the enhancement as show to reference 200:

200. Vinet E, GenestG, Scott S, Pineau CA, Clarke AE, PlattRW, et al. Brief report: causes of stillbirths in women with systemic lupus erythematosus. Arthritis Rheumatol. 2016;68(10):2487-91. https://doi.org/10.1002/art.39742 https://www.ncbi.nlm.nih.gov/pubmed/27159385. This group reviews the incidence and potential risk factors for stillbirth and neurodevelopmental disorders in children born to women with SLE, including in utero exposure to maternal autoantibodies and cytokine levels.

Currently published:

203.• Yousef Yengej FA, van Royen-Kerkhof A, Derksen R, Fritsch-Stork RDE. The development of offspring from mothers with systemic lupus erythematosus. A systematic 
review. Autoimmunity reviews. 2017;16(7):701-711. Epub 2017/05/10. https://doi.org/10.1016/j.autrev.2017.05.005. https://www.ncbi.nlm.nih.gov/pubmed/28479488. This study in mice found significant behavioral alterations in males born to dams exposed to DNRAbs.

204. Lee JY, Huerta PT, Zhang J, Kowal C, Bertini E, Volpe BT. Neurotoxic autoantibodies mediate congenital cortical impairment of offspring in maternal lupus. Nat Med. 2009;15:91-6. https://doi.org/10.1038/nm.1892.

Remove the enhancement for reference 203.

Add the enhancement as shown for reference 204:

204. Lee JY, Huerta PT, Zhang J, Kowal C, Bertini E, Volpe BT. Neurotoxic autoantibodies mediate congenital cortical impairment of offspring in maternal lupus. Nat Med. 2009;15:91-6. https://doi.org/10.1038/nm.1892. This study in mice found significant behavioral alterations in males born to dams exposed to DNRAbs.

Currently published:

207.• Wilken J, Kane R, Sullivan C,WallinM, Usiskin J, Quig M, et al. The utility of computerized neuropsychological assessment of cognitive dysfunction in patients with relapsing-remitting multiple sclerosis. Multiple Sclerosis Journal. 2003;9(2):119-27. This study found that increased hippocampal hypermetabolism and DNRAb serum titers independently predicted poor memory performance, and together provided a more accurate prediction.

208. MackayM, Tang CC, Volpe BT, Aranow C, Mattis PJ, Korff RA, et al. Brain metabolism and autoantibody titres predict functional impairment in systemic lupus erythematosus. Lupus Science \& Medicine. 2015;2(1).

Remove the enhancement for reference 207.

Add the enhancement as shown for reference 208:

208. MackayM, Tang CC, Volpe BT, Aranow C, Mattis PJ, Korff RA, et al. Brain metabolism and autoantibody titres predict functional impairment in systemic lupus erythematosus. Lupus Science \& Medicine. 2015;2(1). This study found that increased hippocampal Hypermetabolism and DNRAb serum titers independently predicted poor memory performance, and together provided a more accurate prediction.

Thank you,

Bruce T. Volpe MD.

Publisher's Note Springer Nature remains neutral with regard to jurisdictional claims in published maps and institutional affiliations. 